\title{
Knowledge, attitudes and practices of sweet food and beverage consumption and its association with dental caries among schoolchildren in Jazan, Saudi Arabia
}

\author{
F.A. Quadri, ${ }^{1}$ H. Hendriyani, ${ }^{2}$ A. Pramono $^{3}$ and M. Jafer ${ }^{1}$
}

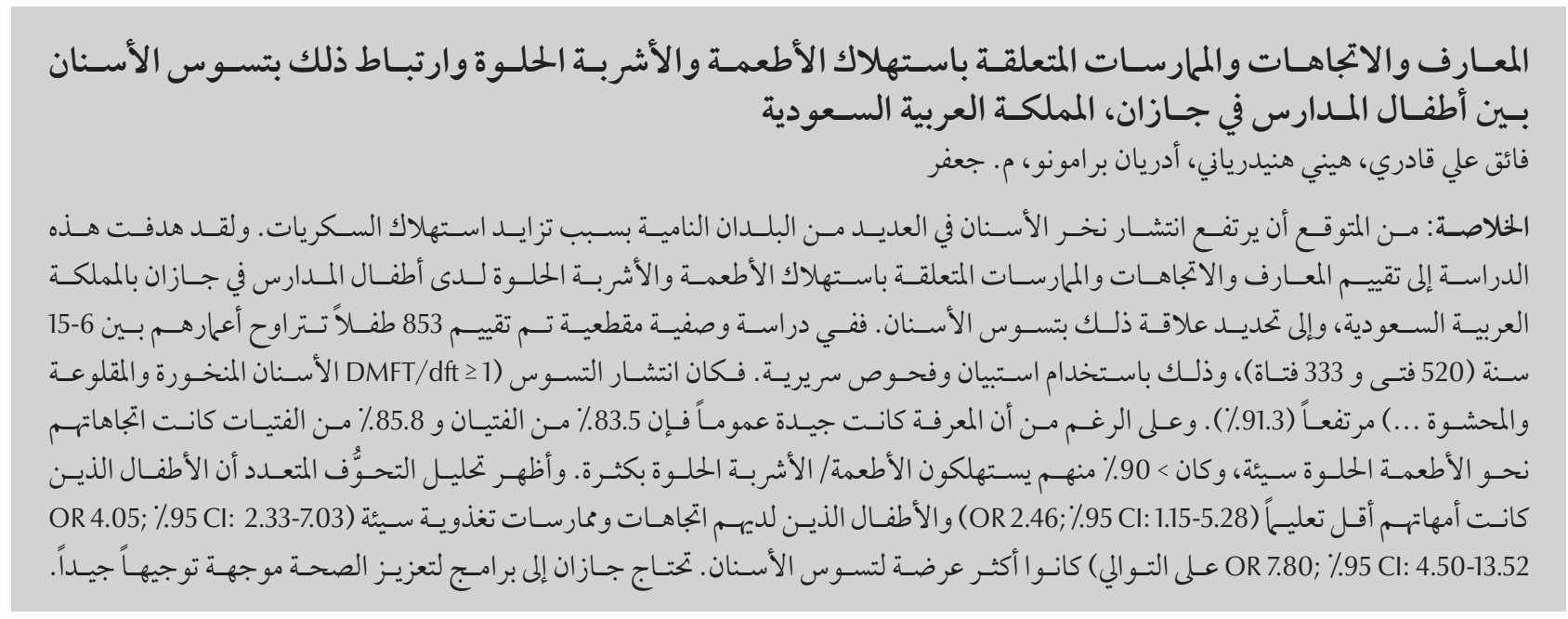

ABSTRACT The prevalence of dental decay is expected to rise in many developing countries due to the growing consumption of sugars. This study aimed to assess knowledge, attitudes and practices of sweet food and beverage consumption among schoolchildren in Jazan, Saudi Arabia and to determine the relationship with dental caries. In a cross-sectional, descriptive study 853 children aged $6-15$ years ( 520 boys and 333 girls) were assessed by questionnaire and clinical examinations. Caries prevalence ( $\geq 1 \mathrm{dft} / \mathrm{DMFT}$ ) was high (91.3\%). While knowledge was generally good, $83.5 \%$ boys and $85.8 \%$ girls had poor attitudes to sweet foods and $>90 \%$ frequently consumed sweet foods/beverages. Multiple regression analysis showed that children whose mothers were less educated (OR 2.46; 95\% CI: 1.15-5.28) and children with poor dietary attitudes and practices (OR 4.05; 95\% Cl: 2.33-7.03 and OR 7.80; 95\% Cl: 4.50-13.52 respectively) were more likely to have dental caries. Well-directed health promotion programmes are needed in Jazan.

Connaissances, attitudes et pratiques en matière de consommation d'aliments et de boissons sucrés et leur association avec les caries dentaires chez des écoliers de Jazan (Arabie saoudite)

RÉSUMÉ Dans de nombreux pays en développement, la prévalence des caries dentaires devrait augmenter en raison de la consommation croissante de sucres. La présente étude visait à évaluer les connaissances, attitudes et pratiques en matière de consommation d'aliments et de boissons sucrés chez des écoliers de Jazan (Arabie saoudite), et à déterminer leur lien avec les caries dentaires. Dans une étude descriptive et transversale, 853 enfants âgés de 6 à 15 ans (520 garçons et 333 filles) ont été évalués à l'aide d'un questionnaire et d'examens cliniques. La prévalence de caries ( $1 \geq$ indice des dents cariées, absentes ou obturées) était forte $(91,3 \%)$. Si le niveau de connaissances était élevé en général, $83,5 \%$ des garçons et $85,8 \%$ des filles avaient de mauvaises attitudes face aux aliments sucrés et plus de $90 \%$ en consommaient fréquemment. Une analyse de régression multiple a démontré que les enfants dont les mères avaient un niveau d'études plus faible (OR 2,46; IC à $95 \%: 1,15-5,28$ ) mais aussi ceux ayant de mauvaises attitudes et pratiques (OR 4,05; IC à $95 \%$ : 2,33-7,03 et OR 7,80; IC à $95 \%$ : 4,50-13,52 respectivement) étaient plus à risque de présenter des caries dentaires. Des programmes de promotion de la santé convenablement ciblés sont nécessaires à Jazan.

'Department of Preventive Dentistry, Jazan University, Jazan, Saudi Arabia (Correspondence to F.A. Quadri: faeq_ali@yahoo.com). 2Department of Nutrition, Polytechnic of Health Semarang, Ministry of Health, Indonesia. ${ }^{3}$ School of Nutrition Science, Faculty of Medicine and Center of Nutrition Research (CENURE), Diponegoro University, Semarang, Indonesia.

Received: 24/11/14; accepted: 27/04/15 


\section{Introduction}

According to the World Health Organization (WHO) dental caries is one of the most common oral diseases; epidemiological studies over the past 20 years have shown an alarmingly high prevalence in children and young adults $(1,2)$. Despite this awareness, a high prevalence of dental caries still exists in many countries worldwide, especially among deprived groups of the population (3).

The prevalence of dental decay is expected to rise in many developing countries and this has been attributed to modernization and the growing consumption of dietary sugars (3). The association of sugar consumption and dental caries is well-established by a variety of research, including human studies, animal experiments and other observational studies (4), and a reduction in caries scores has been observed with lower consumption of sugars $(4,5)$. Knowledge about the intake of sugar in early life is important for caries prevention in adulthood due to children's inclination towards sweet foods and beverages (6). Recognizing early childhood food patterns and preferences is important, as it can influence the choice of nutrient intake in later life (7). For example, a higher intake of sugared soda drinks during school ages persists in adulthood when compared with those who started their consumption after the school years $(8,9)$. Gender differences in terms of sweet food preferences were also reported in a large study of 8900 Danish schoolchildren and young adults (10).

The distribution and severity of caries and related problems show discrepancies between countries and also across different regions within the same nation (3).In Saudi Arabia, despite the extensive network and free availability of dental health services, caries is a major oral health problem among schoolchildren $(11,12)$. A study in Riyadh showed that the prevalence of caries among schoolchildren was $77.7 \%$ (13); 14 years later another study demonstrated a prevalence of $94.4 \%$ among a similar age group (12). Amin and Al Abad suggested that frequent exposure to cariogenic foods among schoolchildren in Saudi Arabia is one of the main risk factors for dental decay (14). Hence, knowing the early dietary behaviour among schoolchildren would help in developing oral health promotion programmes in order to prevent a future rise in the incidence of dental caries in Saudi Arabia $(15,16)$. Jazan region in Saudi Arabia is reported to have a high prevalence of caries among school-age children (17). The current study, the first of its kind in Jazan, aimed to assess the knowledge, attitudes and practices of sweet food consumption among schoolchildren and to determine its relationship to dental caries.

\section{Methods}

\section{Study setting}

The study was conducted in Jazan, which is located at the southern tip of Saudi Arabia bordering Yemen. The population is mostly Arab nationals with some expatriates. To maintain homogeneity among the study population only Saudi nationals were included in the study. The dental examinations and the administration of the questionnaire was done in the school premises.

\section{Study design and sample size}

This was a cross-sectional, descriptive study using multistage random sampling. School-going children within the age range $6-15$ years who agreed to participate were included in the study. The sample size was calculated with absolute precision (0.05), expected proportion (0.5) and estimated designed effect (1). The original sample size after calculation was targeted at 769 and $10 \%$ was added to allow for dropouts among the subjects participating in the study. At first, out of the 4 districts of Jazan region, 3 were randomly selected. In the second stage, a list of schools was obtained and 2 schools ( 1 boys' school and 1 girls' school) from each district were randomly selected: a total of 6 schools. In the third stage, an admission list of schoolchildren was obtained and those whose parents gave consent were recruited for the study. The total sample assessed was 853 , consisting of 520 boys and 333 girls.

The study was approved by the research ethics committee at Jazan University, Saudi Arabia. Official permission to approach the schools was obtained from the regional education office in Jazan. A signed consent was also taken from the parents for the participation of their children in the research study.

\section{Data collection}

\section{Questionnaire}

The questionnaire was adapted from the original version prepared by Gibson (18). The English version of the modified questionnaire was subjected to translation and reverse translation in the local language by bilingual dentists who were fluent in both English and Arabic. A convenience sample size of 20 children was randomly selected and the questionnaire was subjected to validity and reliability tests. To check the reliability of the questionnaire a test-retest procedure and a measure of internal consistency using Cronbach alpha coefficient was calculated (19). The questionnaire was found to be consistent as the minimum value of 0.70 was obtained. The interview was conducted by trained and calibrated dentists (kappa $=0.78 ; 95 \%$ confidence interval (CI): 0.53-0.93).

Questionnaires for children aged 6-8 years were completed on a oneto-one interview basis with the parents. Older children completed the questionnaire themselves and parents or peers of the children were asked to help if the children had difficulty in understanding the questions. Data regarding sociodemographic variables included 
current residence, age in years, parental education, parental occupation and family income. Children's knowledge was assessed by answering 15 questions regarding knowledge about sweet foods that are related to poor oral health. Responses were coded as true or false. Dietary attitude was assessed with 10 questions about attitudes to sweet foods and beverages, with responses scored on a 4-point Likert scale [strongly agree (score 3 ), agree (score 2), disagree (score 1) or strongly disagree (score $0)$ ]. Therefore, the maximum score was 30 and the minimum score was 0 . All items of the questionnaire were phrased in a positive direction. Practice of sweet food consumption was assessed by questions about the frequency with which certain food items or food groups were consumed. Children were asked about the frequency of consumption of a list of 8 foods/beverages, with 7 response options. They were subsequently merged into 2 groups: "frequently" (score 1) (response options: more than once a day, once a day, 3-6 times a week or 1-2 times a week) and "rarely" (score 0 ) (response options: every 2 weeks, once a month or never). Therefore, the maximum score was 8 and the minimum score was 0 .

\section{Caries examination}

Specific days for the clinical examinations were selected and the schoolchildren were examined by trained and calibrated dentists. The examination was under light-emitting diode light, with standard infection control measures implemented such as the use of gloves, masks and disposable diagnostic instruments. Caries status was scored using the WHO recommended method for assessing decayed/missing/filled teeth for deciduous (dft) and permanent (DMFT) teeth. Children obtaining a dft/DMFT score of 0 were classified as caries-free and those who had $\geq 1$ carious teeth were classified as caries active (20).

\section{Data management and processing}

All data information was analysed using SPSS, version 21 . The chi-squared test at $5 \%$ significance was used for assessing the association between independent variables (education of mother and father, occupational status of mother and father, family income, knowledge status, attitude status and practice status) and the dependent variable (caries status). Logistic regression was performed to determine the risk factor for dental caries after adjusting for covariates. For multivariate analysis, the attitude scores were grouped into "good attitude" (agree and agree very much) and "poor attitude" (disagree and disagree very much) and the consumption practices scores were grouped into "frequently" (1-2 times/week, 3-6 times/week, once a day, more than once a day) and "rarely" (every 2 weeks and once a month). Odds ratios (OR) with 95\% CI were also recorded for all variables investigated in the regression logistic analysis.

\section{Results}

\section{Sample characteristics}

The sample contained 520 boys (61.0\%) and 333 girls (39.0\%). The sample distribution according to age and sociodemographic variables by sex is shown in Table 1. It can be seen that $54.9 \%$ of the schoolchildren in the study were aged between 6-9 years, 13.4\% were between $10-12$ years and $31.8 \%$ were between $13-15$ years. The education level of parents revealed that $89.2 \%$ of mothers and $74.6 \%$ of fathers were educated from elementary until high school. Most of the fathers were selfemployed (65.9\%) and 87.7\% were categorized as having a high family income, although data on family expenses were not collected. Comparing the distribution of income between the sexes, it was observed that $5.4 \%$ of girls and $16.7 \%$ of boys were from low-income families
(Table 1), which was a significant difference $\left(\chi^{2}\right.$ test; $\left.P<0.001\right)$.

\section{Dietary knowledge}

Twelve out of 15 questions on knowledge about sweet foods and beverages were answered correctly by more than $60 \%$ of the study sample (Table 2). Three questions were answered incorrectly by a majority of respondents: $71.7 \%$ of boys and $72.9 \%$ of girls had poor knowledge in distinguishing between various forms of sweet foods (question no. 3); 65.9\% of boys and $66.9 \%$ of girls did not know which drinks contained more sweeteners (question no. 4 ); and $56.1 \%$ of boys and $70.8 \%$ of girls thought soft drinks were healthier than fruit juice (question no. 6).

\section{Dietary attitudes and practices}

The percentage of boys and girls who preferred soft drinks to mineral water were $83.5 \%$ and $85.8 \%$ respectively. These results were consistent with their answers about choosing soft drinks rather than mineral water in the dietary knowledge analysis. As many as $94.2 \%$ of boys and $93.4 \%$ of girls preferred sweets to plain bread, and $86.6 \%$ of boys and $96.1 \%$ of girls did not prefer eating snacks with less sugar (Table 3).

The self-reported data about daily intake of sweet foods and beverages revealed that both sexes frequently consumed fruit juice (with sugar), soft drinks, sweets/candy, jam, honey, milk with sugar, chocolate and ice cream (Table 4). Among both boys and girls, $>90 \%$ of the children reported that they frequently consumed soft drinks, sweets, milk with sugar and chocolate.

The mean and standard deviation (SD) scores of dietary attitude for boys and girls was 20.2 (SD 1.9) and 19.5 (SD 1.5) respectively (Figure 1). The mean scores of dietary practice for boys and girls were 8.2 (SD 0.9) and 7.3 (SD 0.8 ) respectively. A significant difference was observed between males and females in attitude scores $(t=4.834$; $P=0.001)$ as well as in practice scores 


\begin{tabular}{|c|c|c|c|c|c|c|}
\hline \multirow[t]{2}{*}{ Sociodemographic variables } & \multicolumn{2}{|c|}{ Boys $(n=520)$} & \multicolumn{2}{|c|}{ Girls $(n=333)$} & \multicolumn{2}{|c|}{ Total $(n=853)$} \\
\hline & No. & $\%$ & No. & $\%$ & No. & $\%$ \\
\hline \multicolumn{7}{|l|}{ Age (years) } \\
\hline $6-9$ & 280 & 53.8 & 188 & 56.5 & 468 & 54.9 \\
\hline $10-12$ & 54 & 10.4 & 60 & 18.0 & 114 & 13.4 \\
\hline $13-15$ & 186 & 35.8 & 85 & 25.5 & 271 & 31.8 \\
\hline \multicolumn{7}{|l|}{ Mother's education } \\
\hline Basic education (elementary or high school) & 476 & 91.5 & 285 & 85.6 & 761 & 89.2 \\
\hline High education (college) & 44 & 8.5 & 48 & 14.4 & 92 & 10.8 \\
\hline \multicolumn{7}{|l|}{ Father's education } \\
\hline Basic education (elementary or high school) & 378 & 72.7 & 258 & 77.5 & 636 & 74.6 \\
\hline High education (college) & 142 & 27.3 & 75 & 22.5 & 217 & 25.4 \\
\hline \multicolumn{7}{|l|}{ Mother's occupation } \\
\hline Employee (government or private) & 87 & 16.7 & 66 & 19.8 & 153 & 17.9 \\
\hline Unemployed (housewife) & 433 & 83.3 & 267 & 80.2 & 700 & 82.1 \\
\hline \multicolumn{7}{|l|}{ Father's occupation } \\
\hline Government employee & 170 & 32.7 & 121 & 36.3 & 291 & 34.1 \\
\hline Private employee & 350 & 67.3 & 212 & 63.7 & 562 & 65.9 \\
\hline \multicolumn{7}{|l|}{ Family income } \\
\hline Low & 87 & 16.7 & 18 & 5.4 & 105 & 12.3 \\
\hline High & 433 & 83.3 & 315 & 94.6 & 748 & 87.7 \\
\hline
\end{tabular}

\begin{tabular}{|c|c|c|c|c|c|c|c|c|}
\hline \multirow[t]{4}{*}{ Item } & \multicolumn{8}{|c|}{ Dietary knowledge of sweet foods and beverages } \\
\hline & \multicolumn{4}{|c|}{ Girls $(n=333)$} & \multicolumn{4}{|c|}{ Boys $(n=520)$} \\
\hline & \multicolumn{2}{|c|}{ False } & \multicolumn{2}{|c|}{ True } & \multicolumn{2}{|c|}{ False } & \multicolumn{2}{|c|}{ True } \\
\hline & No. & $\%$ & No. & $\%$ & No. & $\%$ & No. & $\%$ \\
\hline Taste of food related to oral health & 106 & 31.8 & 227 & 68.2 & 182 & 35.0 & 338 & 65.0 \\
\hline Source of sweet taste of food & 63 & 18.9 & 270 & 81.1 & 132 & 25.4 & 658 & 74.6 \\
\hline Forms of sweet food & 243 & 73.0 & 90 & 27.0 & 373 & 71.7 & 147 & 28.3 \\
\hline Sweetened drinks & 223 & 67.0 & 110 & 33.0 & 343 & 66.0 & 177 & 34.0 \\
\hline \multicolumn{9}{|l|}{ Which contains more sugar: } \\
\hline Mineral water vs fruit juice & 22 & 6.6 & 311 & 93.4 & 37 & 7.1 & 483 & 92.9 \\
\hline Orange vs soft drinks & 236 & 70.9 & 97 & 29.1 & 292 & 56.2 & 228 & 43.8 \\
\hline Apple vs sweets & 47 & 14.1 & 286 & 85.9 & 65 & 12.5 & 455 & 87.5 \\
\hline Grapes vs jam & 64 & 19.2 & 269 & 80.8 & 90 & 17.3 & 430 & 82.7 \\
\hline Oats vs honey & 27 & 8.1 & 306 & 91.9 & 58 & 11.2 & 462 & 88.8 \\
\hline Plain bread vs milk with sugar & 130 & 39.0 & 203 & 61.0 & 133 & 25.6 & 387 & 74.4 \\
\hline Rice vs tea with sugar & 22 & 6.6 & 311 & 93.4 & 42 & 8.1 & 478 & 91.9 \\
\hline Potatoes vs chocolate & 19 & 5.7 & 314 & 94.3 & 18 & 3.5 & 502 & 96.5 \\
\hline Carrot vs ice cream & 2 & 0.6 & 331 & 99.4 & 6 & 1.1 & 514 & 98.9 \\
\hline Fried chicken vs lollypop & 8 & 2.4 & 325 & 97.6 & 14 & 2.7 & 506 & 97.3 \\
\hline Kebab vs dates & 88 & 26.4 & 245 & 73.6 & 145 & 27.9 & 375 & 72.1 \\
\hline
\end{tabular}

$(t=2.998 ; P=0.003)$. Boys had significantly higher scores of both attitude and practice in consuming sweet foods and beverages compared with girls, indicating poorer attitudes and greater consumption (Figure 1).

\section{Dental caries status}

Of the examined schoolchildren 779 (91.3\%) were found to be caries 


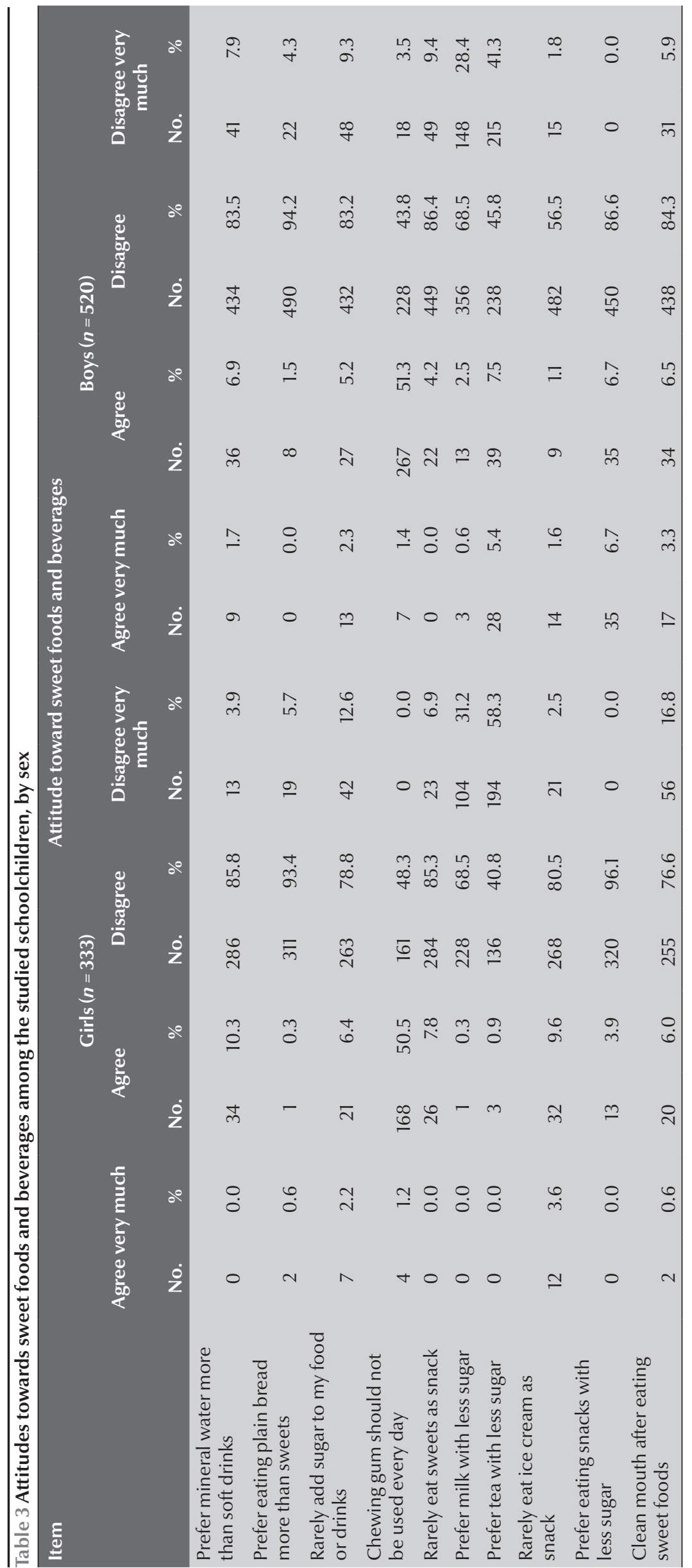

active: 472 (90.8\%) of the boys and 307 (92.2\%) of the girls (Table 5). Male children were more affected with dental caries than were female children, but the difference was not statistically significant $(P=0.471)$.

More of the children who were caries active had poor dietary attitudes when compared with those who were caries free $(94.8 \%$ versus $73.8 \%)(P<$ 0.001) (Table 6). Similarly, children with caries were significantly more likely to have poor dietary practices (96.4\% versus $72.5 \%)(P<0.001)$.

The educational status of the mother was significantly associated with the caries status of their children $(P=0.049)$, but there were no associations with sex, mother's occupational status, father's education or father's occupational status (Table 5).

\section{Logistic regression analysis}

Logistic regression analysis was conducted whereby caries status was kept as the dependent variable while attitude and practice of sweet intake and the educational status of the mother were kept as independent variables (Table 7). Children whose mothers were less educated were more likely to have dental caries compared with children whose mothers were better educated (OR 2.46; 95\% CI: 1.15-5.28). Children with poor attitudes were significantly more likely to have dental caries respectively than the children with good attitude (OR 4.05; 95\% CI: 2.33-7.03). The best predictor for caries status was the practice of consuming sweet foods and beverages (OR 7.80; 95\% CI: $4.50-13.52$ ).

\section{Discussion}

The association of dental caries with the knowledge, attitudes and practices of sweet food consumption among schoolchildren in Jazan, Saudi Arabia was examined. The children with poor attitudes and practices were significantly 


\begin{tabular}{|c|c|c|c|c|c|c|c|c|}
\hline \multirow[t]{4}{*}{ Food item } & \multicolumn{8}{|c|}{ Consumption of sweet foods and beverages } \\
\hline & \multicolumn{4}{|c|}{ Girls $(n=333)$} & \multicolumn{4}{|c|}{ Boys $(n=520)$} \\
\hline & \multicolumn{2}{|c|}{ Frequently } & \multicolumn{2}{|c|}{ Rarely } & \multicolumn{2}{|c|}{ Frequently } & \multicolumn{2}{|c|}{ Rarely } \\
\hline & No. & $\%$ & No. & $\%$ & No. & $\%$ & No. & $\%$ \\
\hline Fruit juice & 281 & 84.4 & 52 & 15.6 & 403 & 77.5 & 117 & 22.5 \\
\hline Soft drinks & 326 & 97.9 & 7 & 2.1 & 506 & 97.3 & 14 & 2.7 \\
\hline Sweets & 325 & 97.6 & 8 & 2.4 & 504 & 96.9 & 16 & 3.1 \\
\hline Jelly & 275 & 82.6 & 58 & 27.4 & 390 & 75.0 & 130 & 25.0 \\
\hline Honey & 261 & 78.4 & 72 & 21.6 & 402 & 77.3 & 118 & 22.7 \\
\hline Milk with sugar & 308 & 92.5 & 25 & 7.5 & 481 & 92.5 & 39 & 7.5 \\
\hline Chocolate & 322 & 96.7 & 11 & 3.3 & 498 & 95.8 & 22 & 4.2 \\
\hline Ice cream & 267 & 80.2 & 66 & 19.8 & 377 & 72.5 & 143 & 27.5 \\
\hline
\end{tabular}

more likely to be caries active, thus confirming this as one of the reasons for caries occurrence among the study sample. These percentages are higher than those reported from another Arab population study in Baghdad, Iraq (21). The high score in attitudes and practices of sweet foods and beverages consumption seen among schoolchildren in the Jazan region could be due to easy access to these items. Most of the Arab nations have experienced a massive growth in their economy in recent decades and this has been shown to have a strong association with elevated consumption of refined sugars among the populations (22). This high per capita sugar consumption among the rich nations has led to a rise in caries occurrence (23).
In accordance with the findings of the current study, previous studies in other countries have also shown a strong association between consumption of sugared foods/beverages and increased rates of caries (24-27). The attitude of schoolchildren in Jazan towards sweet food consumption was in accordance with the study of Ahmed et al. in Iraq, in which 12-year-old schoolchildren preferred sugared snacks or drinks to their regular meals (21).

The reported frequency of consuming sweet foods and beverages, which included soft drinks, sweets, jam, honey, milk with sugar, chocolate and ice cream, was also observed to be high in our study (> 90\% of children consumed these frequently, i.e. once a day, once a day or 3-6 times a week). Therefore, it could be said that the schoolchildren in Saudi Arabia are quite familiar with non-traditional forms of food and beverages. A previous study in Saudi Arabia reported that the adoption of a so-called "Westernized" diet with a high sugar content, without the implementation of proper prevention strategies, could lead to a rise in dental caries among the population (11). Our study also found that a high proportion of schoolchildren were caries active (91.3\%). This agrees with figures from Peterson et al., who in their review of the global burden of oral diseases reported that dental caries was the main oral health problem affecting almost $90 \%$ of schoolchildren throughout the world (2). Our finding is also

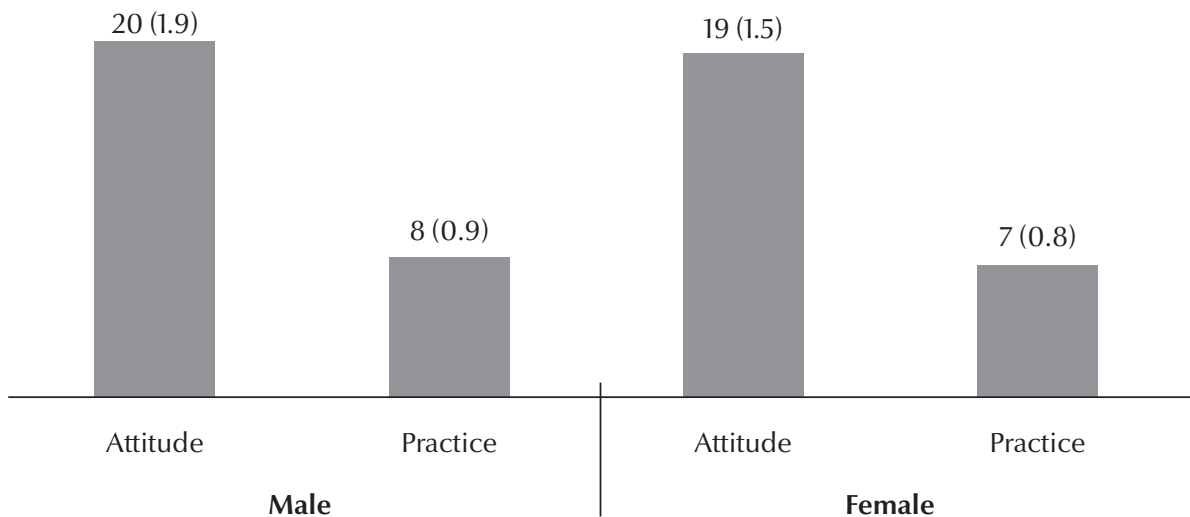

Figure 1 Mean and standard deviation scores on attitudes and practices towards consumption of sweet foods and beverages, by sex (independent $t$-test for differences between boys and girls, $P<0.05)($ boys $n=520$, girls $n=333$ ) 


\begin{tabular}{|c|c|c|c|c|c|}
\hline \multirow[t]{2}{*}{ Variable } & \multicolumn{2}{|c|}{ Caries active $^{\mathrm{a}}$} & \multicolumn{2}{|c|}{ Caries free } & \multirow[t]{2}{*}{$P$-value ${ }^{b}$} \\
\hline & No. & $\%$ & No. & $\%$ & \\
\hline Total & 779 & 91.3 & 74 & 8.7 & \\
\hline \multicolumn{6}{|l|}{ Sex } \\
\hline Boys & 472 & 90.8 & 48 & 9.2 & \multirow[t]{2}{*}{0.471} \\
\hline Girls & 307 & 92.2 & 26 & 7.8 & \\
\hline \multicolumn{6}{|l|}{ Mother's education } \\
\hline Basic education (elementary or high school) & 700 & 92.0 & 61 & 8.0 & \multirow[t]{2}{*}{0.049} \\
\hline High education (college) & 79 & 85.9 & 13 & 14.1 & \\
\hline \multicolumn{6}{|l|}{ Mother's occupation } \\
\hline Employee (government or private) & 139 & 90.8 & 14 & 9.2 & \multirow[t]{2}{*}{0.818} \\
\hline Unemployed (housewife) & 640 & 91.4 & 60 & 8.6 & \\
\hline \multicolumn{6}{|l|}{ Father's education } \\
\hline Basic education (elementary or high school) & 585 & 92.0 & 51 & 8.0 & \multirow[t]{2}{*}{0.244} \\
\hline High education (college) & 194 & 89.4 & 23 & 10.6 & \\
\hline \multicolumn{6}{|l|}{ Father's occupation } \\
\hline Government employee & 266 & 91.4 & 25 & 8.6 & \multirow[t]{2}{*}{0.950} \\
\hline Private employee & 513 & 91.3 & 49 & 8.7 & \\
\hline
\end{tabular}

${ }^{a}$ Based on decayed/missing/filled teeth for deciduous (dft) and permanent (DMFT) teeth. Caries active $=\geq 1 \mathrm{dft} / \mathrm{DMFT}$; caries free $=0 \mathrm{dft} / \mathrm{DMFT}$. ${ }^{b}$ Chi-squared test for association of sociodemographic variables and caries status.

\begin{tabular}{|c|c|c|c|c|c|}
\hline \multirow[t]{2}{*}{ Independent variable } & \multicolumn{2}{|c|}{ Caries active $^{a}$} & \multicolumn{2}{|c|}{ Caries free } & \multirow[t]{2}{*}{$P$-value ${ }^{b}$} \\
\hline & No. & $\%$ & No. & $\%$ & \\
\hline \multicolumn{6}{|l|}{ Dietary knowledge } \\
\hline Poor & 220 & 89.8 & 25 & 10.2 & 0.314 \\
\hline Good & 559 & 91.9 & 49 & 8.1 & \\
\hline \multicolumn{6}{|l|}{ Dietary attitudes } \\
\hline Poor & 675 & 94.8 & 37 & 5.2 & $<0.001$ \\
\hline Good & 104 & 73.8 & 37 & 26.2 & \\
\hline \multicolumn{6}{|l|}{ Dietary practices } \\
\hline Poor & 647 & 96.4 & 24 & 3.6 & $<0.001$ \\
\hline Good & 132 & 72.5 & 50 & 27.5 & \\
\hline
\end{tabular}

${ }^{a}$ Based on decayed/missing/filled teeth for deciduous (dft) and permanent (DMFT) teeth. Caries active $=\geq 1 \mathrm{dft} / \mathrm{DMFT} ; \mathrm{caries} f \mathrm{free}=0 \mathrm{dft} / \mathrm{DMFT}$. ${ }^{b}$ Chi-squared test for association of sociodemographic variables and caries status.

\begin{tabular}{|c|c|c|c|c|c|c|}
\hline \multirow[t]{2}{*}{ Predictors $^{\mathrm{a}}$} & \multicolumn{6}{|c|}{ Association with caries status ${ }^{\mathbf{b}}$} \\
\hline & B & SE & df & $P$-value & Adjusted OR & $95 \% \mathrm{Cl}$ \\
\hline Mother's education & 0.900 & 0.390 & 1 & 0.021 & 2.46 & $1.15-5.28$ \\
\hline $\begin{array}{l}\text { Attitude to consumption of sweet } \\
\text { foods and beverages }\end{array}$ & 1.398 & 0.282 & 1 & $<0.001$ & 4.05 & $2.33-7.03$ \\
\hline $\begin{array}{l}\text { Practice of consumption of sweet } \\
\text { foods and beverages }\end{array}$ & 2.054 & 0.281 & 1 & $<0.001$ & 7.80 & $4.50-13.52$ \\
\hline
\end{tabular}

${ }^{a}$ Caries predictors were coded as $1=$ good, $0=$ poor; ${ }^{b}$ Caries status was coded as $1=$ caries free, $0=$ caries active.

$S E=$ standard error of beta; $O R=$ odds ratio; $C l=$ confidence interval; min. = minimum; max. = maximum. 
consistent with a study conducted by Zailai et al. in a similar population (in Jazan), whereby $89 \%$ of children were seen to be caries active (28). An earlier study conducted in Saudi Arabia by Amin and $\mathrm{Al} \mathrm{Abad}$ found that $68.9 \%$ of male primary-school children were suffering from dental caries (14). The high caries prevalence found among the children in the current study could be attributed to many factors such as poor oral hygiene practice, excessive sweet consumption or inadequate visits to the dentist.

The significant association of caries status with the educational level of mothers and lack of association with the working status of mothers, education of fathers, working status of fathers and sex $(P>0.05)$ were in accordance with another study in the Middle East, in Iraq (21). Hence, better educated mothers have a positive influence on a child's oral health status. In addition, a strong association between caries status and both attitudes and practices of sugared food intake was found, suggesting consumption of higher than normal amounts of sugar among these children had increased the prevalence of dental caries $(5,29)$. This is a matter of great concern as increased sugar consumption could not only lead to dental caries but could also be a factor in other systemic diseases such as childhood obesity and diabetes.

In contrast to the practices followed by these schoolchildren, the questions pertaining to knowledge were answered correctly, indicating that although the children possessed good knowledge their attitudes and practices towards risk factors leading to dental caries were poor. This calls for effective health promotion programmes in the region. It is important that the harmful effects of sugared foods and beverages are understood by the children so that good habits can be implemented in their dietary practices at a younger age. The results of the current study add to the evidence that good dietary behaviour is a key aspect in preventing dental caries. They also stress that among the factors assessed - dietary knowledge, attitudes and practices - the best predictor for caries occurrence was the practice of sweet food consumption.

Apart from the positive aspects of the study design, the study has some limitations. The evaluation of dental caries among the schoolchildren could have been done in a more comprehensive way. For example, we could have divided the carious lesions could into cavitated and non-cavitated and then checked the association with sugared food consumption.

In conclusion, our results provide further evidence that poor dietary attitude and practices of sweet food consumption are associated with active caries status among schoolchildren. We recommend that the impact of consumption of sweet foods and beverages in the country should be further investigated. The study suggests that there is a need for well-directed health promotion and health education programmes among the schools in Jazan, Saudi Arabia.

\section{Acknowledgements}

Funding: The authors would like to acknowledge the research committee at the College of Dentistry, Jazan University for funding the study.

Competing interests: None declared.

\section{References}

1. Bagramian RA, Garcia-Godoy F, Volpe AR. The global increase in dental caries. A pending public health crisis. Am J Dent. 2009 Feb;22(1):3-8. PMID:19281105

2. Petersen PE, Bourgeois D, Ogawa H, Estupinan-Day S, Ndiaye $C$. The global burden of oral diseases and risks to oral health. Bull World Health Organ. 2005 Sep;83(9):661-9. PMID:16211157

3. What is the burden of oral disease? Oral disease burdens and common risk factors [Internet]. Geneva: World Health Organization http://www.who.int/oral_health/disease_burden/ global/en/, accessed 14 May 2015).

4. Moynihan PJ. The role of diet and nutrition in the etiology and prevention of oral diseases. Bull World Health Organ. 2005 Sep;83(9):694-9. PMID:16211161

5. Marshall TA, Levy SM, Broffitt B, Warren JJ, Eichenberger-Gilmore JM, Burns TL, et al. Dental caries and beverage consumption in young children. Pediatrics. 2003 Sep;112(3 Pt 1):e184-91. PMID:12949310

6. Gambon DL, Brand HS, Veerman EC. Dental erosion in the 21st century: what is happening to nutritional habits and lifestyle in our society? Br Dent J. 2012 Jul;213(2):55-7. PMID:22836413

7. Skinner JD, Carruth BR, Bounds W, Ziegler P, Reidy K. Do foodrelated experiences in the first 2 years of life predict dietary variety in school-aged children? J Nutr Educ Behav. 2002 NovDec;34(6):310-5. PMID:12556269

8. Kvaavik E, Andersen LF, Klepp KI. The stability of soft drinks intake from adolescence to adult age and the association between long-term consumption of soft drinks and lifestyle factors and body weight. Public Health Nutr. 2005 Apr;8(2):149-57. PMID:15877908

9. Fiorito LM, Marini M, Mitchell DC, Smiciklas-Wright $\mathrm{H}$, Birch LL. Girls' early sweetened carbonated beverage intake predicts different patterns of beverage and nutrient intake across childhood and adolescence. J Am Diet Assoc. 2010 Apr;110(4):543-50. PMID:20338280

10. Allesen-Holm B, Frost M, Bredie W. Taste sensitivity and preferences in Danish school children. In: Delegate manual: 8th Pangborn Sensory Science Symposium. Copenhagen, Denmark: University of Copenhagen; 2009:26-30.

11. Gandeh MB, Milaat WA, Gandeh M, Milaat W. Dental caries among schoolchildren: report of a health education campaign in Jeddah, Saudi Arabia. East Mediterr Health J. 2000 MarMay;6(2-3):396-401. PMID:11556029

12. Wazzan KA. Dental caries prevalence in 6-7 year old school children in Riyadh region: a comparative study with the 1987 Oral Health Survey of Saudi Arabia Phase I. Saudi Dent J. 2004;16:54-60. 
13. Akpata ES, al-Shammery AR, Saeed HI. Dental caries, sugar consumption and restorative dental care in 12-13-year-old children in Riyadh, Saudi Arabia. Community Dent Oral Epidemiol. 1992 Dec;20(6):343-6. PMID:1464229

14. Amin TT, Al-Abad BM. Oral hygiene practices, dental knowledge, dietary habits and their relation to caries among male primary school children in Al Hassa, Saudi Arabia. Int J Dent Hyg. 2008 Nov;6(4):361-70. PMID:19138188

15. Tahmassebi JF, Duggal MS, Malik-Kotru G, Curzon ME. Soft drinks and dental health: a review of the current literature. J Dent. 2006 Jan;34(1):2-11. PMID:16157439

16. Lee JG, Messer LB. Intake of sweet drinks and sweet treats versus reported and observed caries experience. Eur Arch Paediatr Dent. 2010 Feb;11(1):5-17. PMID:20129028

17. Alzailai A, Quadri MFA, Nayeem M, Inamdar A, Tadakamadla S. Caries status of school children in Jazan city, KSA and its relation with dental literacy of their parents. Journal of Oral Health Research. 2014;5(1):1-5.

18. Gibson RS. Introduction. In: Gibson RS, editor. Principles of nutritional assessment. 2nd ed. New York: Oxford University Press; 2005. pp. 1-26.

19. Tadakamadla SK, Quadri MFA, Pakpour AH, Zailai AM, Sayed ME, Mashyakhy M, et al. Reliability and validity of Arabic Rapid Estimate of Adult Literacy in Dentistry (AREALD-30) in Saudi Arabia. BMC Oral Health. 2014;14:120. PMID:25267119

20. Al-Hebshi NN, Abdulhaq A. Quadri MFA and Tobaigy FM Salivary carriage of Candida species in relation to dental caries in a population of Saudi Arabian primary school children. The Saudi. J Dent Res. 2015;6(1):54-9.

21. Ahmed NA, Astrøm AN, Skaug N, Petersen PE. Dental caries prevalence and risk factors among 12-year old schoolchil- dren from Baghdad, Iraq: a post-war survey. Int Dent J. 2007 Feb;57(1):36-44. PMID:17378348

22. Petersen PE. Challenges to improvement of oral health in the 21st century-the approach of the WHO Global Oral Health Programme. Int Dent J. 2004 Dec;54(6) Suppl 1:329-43. PMID:15631094

23. Woodward M, Walker A. Sugar and dental caries: the evidence from 90 countries. Br Dent J. 1994 Apr 23;176(8):297-302. PMID:8186040

24. Ismail AI, Burt BA, Eklund SA. The cariogenicity of soft drinks in the United States. J Am Dent Assoc. 1984 Aug;109(2):241-5. PMID:6590604

25. Sohn W, Burt BA, Sowers MR. Carbonated soft drinks and dental caries in the primary dentition. J Dent Res. 2006 Mar;85(3):262-6. PMID:16498075

26. Armfield JM, Spencer AJ, Roberts-Thomson KF, Plastow K. Water fluoridation and the association of sugar-sweetened beverage consumption and dental caries in Australian children. Am J Public Health. 2013 Mar;103(3):494-500. PMID:23327241

27. Mattila ML, Rautava P, Sillanpää M, Paunio P. Caries in fiveyear-old children and associations with family-related factors. J Dent Res. 2000 Mar;79(3):875-81. PMID:10765963

28. Zailai AM, Quadri M, Nayeem M, Inamdar A, Tadakamadla SK. Caries status of school children in Jazan city, KSA and its relation with dental literacy of their parents. J Oral Health Res. 2014;5(1):1-6.

29. Iftikhar A, Zafar M, Kalar M. The relationship between snacking habits and dental caries in school children. Int J Collab Res Intern Med Public Health. 2012;4(12):1943-51. 